

\section{Teatro - Educação e ludicidade: novas perspectivas em educação}

\begin{abstract}
RESUMO: O presente trabalho tem como objetivo desenvolver algumas reflexões acerca dos novos paradigmas didáticos que aportam como alternativas para superar as dificuldades apresentadas pelos educadores perante o trabalho pedagógico. A metodologia configurou-se como uma pesquisa bibliográfica acerca dos principais autores que atualmente referenciam educadores e pesquisadores da área da Arte-Educação,Teatro-Educação e da ludicidade. O trabalho com o Teatro-Educação configura-se a partir de pressupostos da ludicidade, como plenitude do educando, consciência dos docentes no trabalho a ser desenvolvido, corporeidade privilegiada e contextualização social. Aportamos, então, com uma abordagem didática que preconiza a educação de uma forma crítica, mas também priorizando os aspectos da emoção, da sensibilidade, do corpo e da consciência no trabalho pedagógico.
\end{abstract}

PALAVRAS-CHAVE: teatro-educação; educação e ludicidade.

\section{Introdução}

Com o presente artigo, desenvolvido a partir de uma revisão bibliográfica sobre o tema em questão, objetivamos discutir as contribuições acerca do Teatro-Educação como componente lúdico no processo de uma educação crítica e multirreferencial. Tentaremos trilhar caminhos epistemológicos na busca desse encantamento motivador das transformações e das expressões humanas.

O teatro e a ludicidade, enquanto processos que se interpenetram e possibilitam intensa motivação subjetiva, devem ser concebidas como um campo de significativa experiência emocional e intelectual, que pode (e deve) focalizar a diversidade de gênero, de classe e de grupos sociais envolvidos no processo de educação. Daí, provém a sua vocação emancipadora que, como processo, pode construir juntamente com os educandos, condições de percepção/descortinamento e apreensão de sua realidade, bem como alternativas, visando uma dada transformação das amarras opressivas de cunho cultural e econômico.

Perante tais perspectivas que assolam nossa educação atual: altos índices de repetência, evasão escolar, professores mal re-

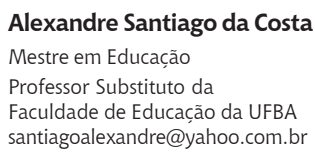


munerados, greves constantes da classe docente, métodos e teorias de ensino sendo impostos verticalmente, violência nas escolas, apatia das classes docente e discente, que sabemos terem raízes muito mais profundas e complexas: o que fazer? Não pretendemos uma resposta pronta, acabada, estanque e definitiva, procuramos fortalecer elementos e linguagens que neste momento nos é possível vislumbrar. Dentro dessa possibilidade, vislumbramos a Arte, o Teatro-Educação e a Ludicidade, como componentes essenciais no processo de um (re) encantamento do processo educativo.

Os docentes têm muito a ganhar com tais discussões, haja vista, que o lúdico e a arte, contemplam o político, o afetivo, o estético, a ética, a crítica e a "intereza" na relação humana, partindo do pressuposto de que a educação precisa dessa "intereza" e dessa plenitude em seu processo (Luckesi,2002).

O que seria mesmo essa nova abordagem, que preconiza a arte e a ludicidade enquanto catalisadores dos processos de ensino-aprendizagem? Uma arte por si só já não seria educativa (abordagem essencialista)? Que elementos novos essa Arte-Educação traz para o cenário da Pedagogia e, em específico, para subsidiar a grande quantidade de projetos sociais (ONG) em Arte-Educação que trabalham, ou pretendem trabalhar nesta perspectiva junto à sociedade civil atual?

Tais questões merecem uma devida análise crítica. Para tanto, podemos fazer uma "trilha" epistemológica, em busca da gênese e das principais idéias que fomentam a discussão acerca da Arte, da ludicidade e da educação, correlacionando-as, e discutindo como tais idéias inserem-se no contexto de uma pedagogia crítica.

\section{Teatro-Educação; novas possibilidades estéticas em educação.}

A Estética, embora não iremos nos deter profundamente nessa discussão, tem grande influência no processo educacional, haja vista que concebe linguagens para trabalhar determinada formação sociocultural. Para tanto, novas (re)significações e demandas por transformações requerem novas formas e linguagens de trabalhar os conteúdos e saberes que se consideraram fundantes no processo de mobilização social. O Teatro-Educação, então, preconiza uma estética particular para esse trabalho com 
educandos provenientes das classes populares ou em situação de risco social. Portanto, o potencial político da arte baseia-se, além de outros componentes importantes, na sua dimensão estética e ética.

A arte vem sendo preterida em favor de conhecimentos e fatores pragmáticos na evolução dessa humanidade. Um dos males da nossa sociedade, imersa nessa condição pós-moderna1, é a angústia da própria condição humana. Os escapes dessa condição angustiante só são sentidos e saboreados por uns poucos, consistindo um privilégio dos que dispõem de acesso ao lazer e ao ócio. Esse ócio, que segundo o Filósofo Domenico de Masi, é extremamente necessário e criativo, precisando ser estendido a todos, como uma tentativa de devolver a esse homem sua natureza lúdica e não apenas racional e pragmática, pois a arte nutre a humanidade de uma gama de saberes, que muitas vezes o intelecto não consegue expressar, como menciona Barbosa (1991):

A arte é um rio cujas águas profundas irrigam a humanidade com um saber outro que não o estritamente intelectual, e que diz respeito à interioridade de cada ser. A vida humana se confunde, em suas origens, com as manifestações artísticas ( p.12).

O teatro-Educação, então, possibilita a transcendência da realidade imediata, destruindo a objetividade reificada das relações sociais estabelecidas e abre uma nova dimensão da experiência, o renascimento da subjetividade rebelde, necessária aos dias de hoje. Há que se planar sobre as cabeças humanas o "belo" e o cruel, para vislumbrarmos as mais altas esperanças de um futuro feliz (Artaud, 202).

Então, a arte é necessária para que o homem se torne capaz de conhecer e modificar esse mundo, num processo dialético, mas também, é necessária pela subjetividade e simbolismo que outorgam as experiências humanas, num movimento de uma "possível utopia", como escreve Linhares (1999):

O trabalho com a utopia é, necessariamente, um campo tenso, onde se trabalha o que se vê do real, do modo como ele se apresenta hoje e seus possíveis. Isso quer dizer que quando se mira a fantasia, o desejo, o sonho, também se está criando um campo de tensão entre o não-ser-ainda dessa "realidade" e o que temos hoje. Está se lidando com o progresso 
Tal reflexão de Linhares é muito similar ao que aponta a teoria do dramaturgo Bertolt Brecht, que preconiza um teatro em que seus espectadores entendam que sua situação social é um estado provisório e não uma realidade instituída e intrínseca a sua vida, mas sim, com possibilidades de mobilidade. Nietzsche (2002) também colabora com esse constructo a que estamos tentando elucidar, com a idéia de vontade de potência, um vir a ser, almejando uma cultura que estraçalhe subjetividades numa experiência estética cruel e marcantemente simbólica. Segundo esse autor, mais um século de extrema racionalidade e livros, a humanidade cheirará mal, e diz que precisamos sair da condição de miseráveis culturais, e aportar com a arte em seu sentido mais lúdico e transformador, plantando as mais altas esperanças do ser humano nessa humanidade.

A cultura, encarada como uma teia subjetiva de significados, permeados pela política, ética, poder, arte, entre outros aspectos que fundam os alicerces da subjetividade coletiva de determinado grupo social, insere-se nessa discussão como importante fenômeno reflexivo da sociedade, num processo simbiótico e de interpenetração nas vidas dos indivíduos. Segundo Marcuse (1970), é na subjetividade que está o motor e potência dessa transformação. Assim, é minimizado um importante pré-requisito da revolução, nomeadamente, o fato de que a mudança radical e cultural deve basear-se na subjetividade dos próprios indivíduos, na sua inteligência e nas suas paixões, nos seus impulsos e nos seus adjetivos. Nesse viés, percebemos o quão importante é utilizarmos uma linguagem em Arte-Educação que reflita os conflitos inerentes à vida desses educandos e que se utilize e reflita em uma abordagem contextualizada e visceral, por parte dos educandos.

Então, é na cultura, e a escola insere-se nesse contexto cultural, que se dão verdadeiros duelos ideológicos visando determinados objetivos sociais, como a reprodução e/ou a resistência. Henry Giroux (2000), esclarece-nos um pouco sobre esse embate social no campo da cultura, e a função de uma pedagogia crítica:

A cultura nem flutua por qualquer lugar, nem tampouco está estancada, no entanto, tal conhecimento sugere mais do que um reconhecimento da cultura como terreno de luta [...] os trabalhadores e as trabalhadoras culturais devem aprofundar-se no significado político por meio da produção de práticas pedagógicas que impliquem e desafiem essas estratégias re- 
presentativas, maquinarias, materiais e tecnologias de poder, que condenaram e estão condicionados pelo jogo indeterminado do poder, conflito e da opressão dentro da sociedade ( p.70)

A cultura consiste, então, num campo social no qual o poder muda repetidamente e as identidades estão constantemente em trânsito, onde o indivíduo é freqüentemente situado onde menos the cabe e sim onde lhe é imposto, seus desejos, sua sexualidade, seu lazer, são direcionados para onde o capital direciona, seja através de processos simbólicos ou de determinação explícita de cunho econômico, por exemplo.

Faz mister, então, uma prática pedagógica que arrisque uma transgressão e uma subversão interdisciplinar que se conectem de forma complexa, com efetivos projetos com vistas a melhorar a democracia racial, econômica, política e cultural, e percebemos na ludicidade e no teatro-educação, importantes contribuições nesse sentido.

Mas não podemos limitar a arte. É verdade que uma das funções essenciais dela, tomada como um elemento não apenas estético, é transformar o mundo, mesmo que simbolicamente e apresentando-se como uma "lupa social", esclarecendo e incitando a ação. Mas é igualmente verdade que não podemos descartar o resíduo mágico e lúdico que a arte proporciona, uma vez que sem esse resíduo a arte deixa de ser arte, pois, segundo Fisher: "A arte é necessária para que o homem se torne capaz de conhecer e mudar o mundo. Mas a arte também é necessária em virtude da magia que lhe é inerente" (p.20).

Percebemos então, numa perspectiva sociocultural, o quão importante é a arte nesse processo de constituição e de "descortinamento" de uma dada realidade social. Expressando não apenas de forma mágica a realidade, como também pode contribuir para constituir essa realidade. As qualidades revolucionárias da arte, a sua acusação da realidade estabelecida e injusta socialmente e seu progresso baseiam-se nas dimensões em que a arte transcende a sua determinação social e se emancipa a partir do universo real do discurso e do comportamento. Assim, a arte cria o mundo em que a subversão da experiência da própria arte se torna possível.

Herbert Marcuse, em seu livro A Dimensão Estética(1970), pontua, baseado na teoria marxista, idéias para o confronto da arte 
nessa sociedade capitalista e cada vez mais complexa do ponto de vista da produção e da comercialização de bens simbólicos e materiais. Há de se preconizar uma estética que esteja atrelado ao conhecimento artístico leva a uma não privatização do social, a negação da sublimação da realidade posta, contrapondo-se a idealização do amor e da morte, pois, são muitas vezes, segundo a estética marxista, uma ideologia conformista e repressiva. A estética marxista condena a transformação dos conflitos sociais em destino pessoal, a abstração da situação de classe, o caráter "elitista" dos problemas, a autonomia ilusória dos protagonistas (Marcuse, 1970).

A arte, no atual estágio dessa civilização, desigual e propulsora de injustiças, precisa desse artista com este nível de consciência social. Numa sociedade em decadência ou ascensão, a arte para ser verdadeira precisa refletir também esses aspectos, a menos que ela queira ser infiel à sua função social. Contudo, precisa mostrar o mundo como passível de ser transformado, e ajudar em tal transformação. A arte é propriamente uma realidade social, e a sociedade precisa desse artista, este supremo feiticeiro, e tem o direito de pedir-lhe que ele seja consciente de sua função, Fischer (1987).

A ludicidade nos traz importantes elementos que nos fazem pensar sobre nossa realidade, nossa sociedade, a relação do "eusocial" com o "eu-individual" (Luckesi, 2002). Se a ludicidade nos faz perceber e atentar para nosso contexto, o que fazer quando nos percebemos inseridos em uma realidade injusta socialmente? A ludicidade, além dessa conscientização do ser, também congrega elementos como a práxis dentro desse pressuposto dialético.Segundo Marcuse (1970):

... o que na arte parece distante da práxis da mudança deve ser reconhecido como um elemento necessário numa práxis futura de libertação como a "ciência do belo", a "ciência da redenção" e da realização. A arte não pode mudar o mundo, mas pode contribuir para a mudança da consciência e impulsos dos homens e mulheres, que poderiam mudar o mundo.(p.43)

A ludicidade e a arte não são fundantes dessa transformação social, mas são esclarecedoras e conscientizadoras dessa práxis revolucionária; a consciência social é o primeiro passo na busca 
dessa conquista por melhores condições de vida. É chegada a hora de unirmos nossas ferramentas, o artista com sua arte, o educador com a educação, o escritor com suas palavras, o agricultor com sua enxada, na busca dessa conscientização e dessa transformação, pois, segundo Bertolt Brecht, só existe um aliado contra o barbarismo crescente; são as pessoas que sob ele sofrem. Só dessas pessoas podemos esperar alguma coisa, por isso o educador, o artista, o agricultor, o escritor, devem virar-se para o povo, um povo que faz a história, que transforma o mundo e se transforma a si mesmo, e é mais necessário do que nunca falar a sua linguagem, a linguagem do povo, a linguagem da transformação (inspiração backhtiniana).

Para ilustrar, lanço mão da literatura, nas palavras de Érico Veríssimo, sobre a função do escritor no mundo, que transpomos também para nossa prática de educadores que preconizamos uma pedagogia crítica, que utiliza a ludicidade e a arte na construção de uma sociedade mais feliz e justa, vejamos o trecho a seguir:

Lembro-me de que certa noite eu teria uns quatorze anos, quando muito encarregaram-me de segurar uma lâmpada elétrica à cabeceira da mesa de operações, enquanto um médico fazia os primeiros curativos num pobre-diabo que soldados da Polícia Municipal haviam carneado. (...) Apesar do horror e da náusea, continuei firme onde estava, talvez pensando assim: se esse caboclo pode agüentar tudo isso sem gemer, por que não hei de ficar segurando esta lâmpada para ajudar o doutor a costurar esses talhos e salvar essa vida? (...) Desde que, adulto, comecei a escrever romances, tem-me animado até hoje a idéia de que o menos que o escritor pode fazer, numa época de atrocidades e injustiças como a nossa, é acender a sua lâmpada, fazer luz sobre a realidade de seu mundo, evitando que sobre ele caia a escuridão, propícia aos ladrões, aos assassinos e tiranos. Sim, segurar a lâmpada, a despeito da náusea e do horror. Se não tivermos uma lâmpada elétrica, acendamos os nossos toco de vela ou, em último caso, risquemos fósforos repetidamente, como um sinal de que não desertamos nosso posto. Veríssimo (1978).

A arte, a ludicidade e a educação emergem como um processo motivador, extremamente complexo, de mobilização da ação humana, como manifestação cultural instigante, pois se trata de uma linguagem e de um sistema simbólico de representação hu- 
mana, de natureza histórico-social milenar. A ludicidade comunga com processos de plena motivação, consciência pessoal e social, bem como, processos, de intenso prazer estético. A educação constitui um dos processos centrais na formação humana, com linguagens diversas, sistêmicas ou não, atreladas a intencionalidades sociais ou de reprodução técnico-científicas, constituindo sempre um importante instrumento na formação cultural da humanidade. Esses três elementos (arte, educação e ludicidade) correlacionando-se, num processo dialógico e multirereferencial.

\section{3-O teatro e suas possibilidades educacionais}

O teatro constitui uma poética/linguagem estética que evolui há milhares de anos. No compasso das transformações sociais, ele vai se transformando e recriando-se à medida que o homem e a sociedade também entram nessa "roda viva". Escrever sobre teatro é também escrever sobre o homem e sua trajetória em busca de si e do mundo.

O teatro é rito. E sendo rito é cultural. E sendo cultural é humano. Sendo cultura, rito e humano sua proximidade com a educação é necessária, haja vista que a educação participa de rituais de aprendizagens, devendo sempre levar em consideração o ser humano e sua cultura. Então como podemos escrever e relacionar rito, teatro e educação?

Há um grande contingente de descobertas educacionais sobre o caráter pedagógico, terapêutico e semiótico do teatro interagindo com as pesquisas estéticas que ambicionam a renovação da linguagem do teatro e das artes como um todo por todo o século XX e XXI. Algumas experimentações e propostas estéticas contemporâneas influenciaram e continuam influenciando as diferentes abordagens do teatro na educação. Contudo, emergiu nos últimos tempos, um amplo leque de possibilidades, uma espécie de mosaico de encaminhamentos pedagógicos do trabaTho educativo com teatro (Japiassu, 2001).

Como alocamos o teatro no processo de educação, é necessário elencarmos as possíveis particularidades e especificidades dessa forma de trabalho humano. Há particularidades no que tange ao teatro como forma espetacular e o teatro como perspectiva didática em dada formação educacional. Nosso objeto de estudo refere-se à segunda perspectiva, que tomamos por base alguns 
elementos do teatro em geral para subsidiar-nos no trabalho de Teatro-Educação.

O Teatro-Educação também caminha em outra direção em relação ao teatro pedagógico, que consiste numa forma de instrumento ou ferramenta pedagógica na educação. Mas o TeatroEducação vai além dessa abordagem contextualista ou instrumental que difere da perspectiva essencialista ou estética que defende a presença do teatro em situações de aprendizagens seja na escola ou em outros espaços educacionais. O teatro e as artes em geral, nessa perspectiva estética e essencialista, são concebidos como linguagens, como um conjunto de linguagens semióticas de representação, especificamente humanas.

O teatro e as artes em geral, segundo Vigotski (1989), são verdadeiras formas e "instrumentos" de expressão semiótica, com vias de processos de representação simbólica para a comunicação do pensamento do ser humano.Tal perspectiva eleva o valor da arte e a articula como importante elemento na formação do educando. O uso dos símbolos e da expressão humana como catalisadores dos processos educacionais são importantes "instrumentos" psicológicos que afetam de forma irreversível o funcionamento mental humano, bem como a estrutura das relações entre pessoas intra e interculturalmente.

O "drama" ou o teatro esteve sempre muito próximo à educação, pois percebeu-se cedo as benesses do teatro no processo educacional. Nos primórdios da história da educação brasileira, o teatro foi um importante instrumento da pedagogia jesuítica, pois segundo Farias ( 2001):

O teatro, que foi trazido pelos jesuítas para a nova terra de 1549, ali chegou como instrumento de catequese. Na imensidão daquele fim de mundo, o teatro era o livro de leitura, a principal técnica pedagógica, e, ao mesmo tempo em que os espetáculos incorporavam alguns dos cantos e danças dos índios, e acrescentavam a mímica e a oratória, contribuíam para apagar a cultura própria dos habitantes daquela terra.(p.3)

Seria então Padre José de Anchieta o primeiro a utilizar o Teatro e o Teatro-Educação no Brasil? É atribuída a ele a maioria das obras teatrais do Brasil do século XVI. Aqui se percebe uma fusão no que diz respeito ao teatro como forma espetacular e o teatro como instrumento educacional, pois, ao mesmo tempo 
em que a maioria dos índios. Eram os próprios jesuítas que escreviam os textos e organizavam as representações, que eram não só destinadas aos índios, mas, também, aos brancos, nobres, plebeus e negros. Era de interesse da igreja católica a conversão e fortificação dos ideais cristãos; para isso, até a língua dos índios, seus ritos, danças, cantos, foram utilizados no teatro para uma melhor comunicação com o público em geral, não priorizando apenas certa parcela da população. Os evangelizadores aperfeiçoavam assim, seu teatro-educação, adaptando o conteúdo das suas mensagens às tradições e à mentalidade dos indígenas.

Contudo, essa metodologia de trabalho tornou-se um componente crucial na formação dos novos cristãos do catolicismo na nova colônia de Portugal. O teatro possibilitava, então, o uso dos elementos contextuais dos indígenas a serem usados no seu próprio etnocídio. Não posso deixar de fazer um paralelo com a atualidade, que pressupõe o uso da própria cultura popular como mecanismo de dominação na sociedade brasileira. O que geralmente os discursos chamam de valorizar a cultura dos povos vem travestido de uma tentativa de não possibilitar o povo ao acesso dos bens simbólicos da humanidade, condição sine qua non para a subordinação.

O teatro ou o "drama" trazidos para o âmbito da educação é também proveniente das mais variadas ascensões no campo da evolução da Pedagogia. O interesse em aspectos diversos do comportamento humano e dos processos de aprendizagem fazem emergir vários elementos de constituição didática, como aponta Courtney apud Japiassu (2001):

Segundo Richard Courtney (1981,p.42), "a formulação da idéia básica de que a atividade dramática era um método bastante efetivo de aprendizagem deveu-se principalmente a Caldwell Cook (...) a primeira formulação do método dramático foi a de Caldwell Cook em 'The Play Way (1917)" . De acordo com Courtney, o papel do teatro na educação escolar passou a ser destacado só a partir da difusão das idéias de uma educação "pedocêntrica", inspirada no pensamento filosófico e educacional de JeanJacques Rousseau. (p.18)

Entendemos, então, que o advento de novas concepções da criança e do processo de ensino e aprendizagem, bem como das novas tecnologias pedagógicas fornecem uma gama de novas 
perspectivas no que tange ao trabalho educacional. Outro exemplo, além das idéias de Rousseau acerca da criança e de sua educação que muito influenciou a educação, foi a Escola ativa, movimento educacional surgido a partir das idéias de vários educadores, onde se destaca Jonh Dewey. Tais educadores da Escola Ativa colocam o processo de ensino e aprendizagem proveniente da valorização da atividade espontânea e os interesses das crianças, possibilitando uma aproximação muito forte da educação com as artes.

A partir da segunda metade do século XX, com o advento de novas possibilidades didáticas, inclusive a educação através da arte concebida e difundida por Herbert Read, o teatro era analisado sob o ponto de vista de uma dimensão pedagógica.Tentando superar as limitações instrumentais do teatro, que comumente era visto como ferramenta, método ou instrumento didático, surgem novos estudos no que tange ao teatro e à educação, que de acordo com Japiassu (2001):

Essa nova abordagem do ensino do teatro, essencialista ou estética, fundamentou-se na especificidade da linguagem teatral e, ao mesmo tempo, buscou-se compreender seus princípios psicopedagógicos. O eixo dessa perspectiva pedagógica teatral é a compreensão do teatro como sistema de representação semiótico, como forma de expressão artística e linguagem acessível a todo ser humano- e não apenas a um pequeno grupo de iniciados (profissionais de teatro ou aficcionados do teatro amador). (p.22)

$\mathrm{Na}$ atualidade, há de se chamar a atenção para algumas convenções e estratégias teatrais que vêm sendo aplicadas ao ensino nas escolas brasileiras, como elementos facilitadores da aquisição e fixação de conhecimentos. Entretanto, segundo Cabral (1998), o uso de técnicas teatrais por si só, distanciadas de um contexto dramático, não vai além de possibilitar uma estratégia dinâmica para facilitar a transmissão de conhecimentos e saberes. A autora analisa ainda que o potencial estético do teatro na educação, de conhecer e sentir (envolvimento emocional), construir e expressar-se (aluno como produtor de conhecimentos) perde-se ao separar as técnicas teatrais de seu contexto dramático.

O teatro na educação, ainda hoje, é pensado exclusivamente como um meio eficaz para alcançar conteúdos disciplinares extrateatrais ou objetivos pedagógicos muito amplos. Há uma 
importante vertente dessa perspectiva, e que vale a pena ser discutida aqui que denomina-se Play Way ou Método Dramático. O método dramático é um recurso didático que consiste na encenação didática de situações para a assimilação de conteúdos trabalhados pelas diferentes disciplinas do currículo. Há mordazes críticas a essa perspectiva, eu a concebo como mais uma possibilidade da utilização do teatro, diferente entretanto do Teatro-Educação. Considero importante explicitar um pouco as idéias acerca dessa proposta.

Uma das principais fomentadoras dessa perspectiva no Brasil é a pesquisadora Dra.Beatriz Cabral da Universidade Federal de Santa Catarina que desenvolve importantes estudos na linguagem do teatro aplicado à educação que se denomina Drama como método de ensino, utilizando-se do "drama" como instrumento estético no fazer educacional. Contudo, está longe de ser um mero instrumento de repasse de conteúdos escolares, mas avança nessa perspectiva, pois, segundo Cabral (1998):

A singularidade do drama como processo é que é possível considerá-lo tanto como método de ensino, permitindo abordar e desenvolver qualquer tema ou situação dentro ou fora do currículo; quanto como eixo curricular, podendo ser caracterizado como uma atividade independente das demais disciplinas. Mas capaz de gerar interesse ou pontos de ligação com qualquer outra das áreas curriculares.(p.19)

Com a educação, contudo, distingue-se um pouco do que chamamos de Teatro-Educação. O drama como método, eixo curricular e/ou tema gerador surgiu inicialmente nos países de língua inglesa e de acordo com Cabral (1998):

Constituindo-se atualmente numa sub-área do fazer teatral e baseado num processo contínuo de exploração de formas e conteúdos relacionados com um determinado foco de investigação (selecionado pelo professor ou negociado entre professor e alunos). Como processo, o drama articula uma série de episódios, os quais são construídos e definidos a partir de convenções teatrais criadas para possibilitar seu sequenciamento e aprofundamento. (p.12)

O Drama como método de ensino possui três características básicas: o processo, o pré-texto e os episódios. O processo em 
drama é a negociação e a renegociação dos elementos da forma dramática, incorporando o contexto e objetivos dos participantes. O pré-texto é a forma como a atividade ou o tema é introduzido no grupo, como o envolvimento emocional e intelectual com o processo. Os episódios são os fragmentos ou eventos que fazem parte de sua estrutura narrativa (Cabral,1998).

Há uma importante constatação que percebemos no Drama como método de ensino e no Teatro-Educação é que as dimensões artísticas e a dimensão educacional alimentam uma a outra. Tal perspectiva faz com que a experiência teatral transforme a compreensão ou o entendimento dos participantes em nível pessoal, social, estético e artístico.

Como recurso metodológico, o "drama" tem freqüentemente aparecido nas diversas instituições de ensino no Brasil e no mundo, muitas vezes, com um caráter bem instrumental e limitador das possibilidades que lhe são inerentes. Há uma grande freqüência também do aparecimento de bibliografia e estudos sobre o tema, para socializar aos educadores o potencial do drama, que segundo Cabral (1998), ativa, simbióticamente, objetivos educacionais e expressivos.

Com a metodologia do teatro/drama há possibilidades de penetrarmos em novas possibilidades de interação e comunicação. Podemos entrar em uma situação imaginária, no contexto da ficção, embora, muitas vezes, tenhamos que atuar sobre as realidades concretas e reais; contudo, a ficção não deixa de ser uma possibilidade de construção de alguns conhecimentos. A aprendizagem deste modo emerge de situações e ações que nem sempre estão presentes em nosso cotidiano, mas que contribuem para nosso progresso cultural e crítico-social. O contexto da ficção permite outro ponto importante, focalizar e desafiar aquilo que é normalmente aceito sem questionamentos, tudo que é assumido como anestesiante e que na ficção torna um grau de estranhamento..

Portanto, essa abordagem de Teatro-Educação constrói, pelo processo do teatro ou das outras linguagens em arte-educação permeada pela ludicidade, instrumentos poderosos de comunicação, leitura e apreensão da realidade humana. Não há uma preocupação máxima com a formação do artista, mas sim, o domínio "tecnológico" da comunicação e expressão teatral, movimentando-se numa área permeada pela afetividade, cognição, psicomotricidade e ética. 
ABSTRACT: The present work aims to develop some reflexions about the nem didactic paradigms that appear an alternative to overcome the difficulties brought by the teachers educations towards the pedagigic work. The methodology was configurated as a bibliographic research about the main authors that are nowadays a reference to educators and researchers in the art-education, play way and playfulness area. The work with art-education is shaped from the pressupositions of the playfulness theory, such as: the plenitude of the student, the awareness of the teachers on the work snat is about to be developed, privileged body awareness and social contextualitation. we base on an educational approach that extols a critical form of education, but algo gives priority to the aspects of emotio, sensitivity, the body and the awareness on the pedagogic work.Abstract: The present work aims to develop some reflexions about the nem didactic paradigms that appear an alternative to overcome the difficulties brought by the teachers educations towards the pedagigic work. The methodology was configurated as a bibliographic research about the main authors that are nowadays a reference to educators and researchers in the art-education, play way and playfulness area. The work with art-education is shaped from the pressupositions of the playfulness theory, such as: the plenitude of the student, the awareness of the teachers on the work snat is about to be developed, privileged body awareness and social contextualitation . we base on an educational approach that extols a critical form of education, but algo gives priority to the aspects of emotio, sensitivity, the body and the awareness on the pedagogic work.

KEY WORDS: play way, wducation and playfulness key-words: play way, wducation and playfulness

\section{Referências}

BARBOSA, Ana Mae. A imagem no ensino da arte. São Paulo: editora Perspectiva, 1991.

BRECHT, Bertolt. Estudos sobre teatro. Lisboa:1957.

BRASIL. Ministério da Educação. Parâmetros Curriculares Nacionais. Volume 6: Brasília, MEC, 1999.

CABRAL, Beatriz. Arte em foco. Santa Catarina: Imprensa Universitária, 1998.

FISCHER, Ernst. A necessidade da arte. $9^{a}$ edição. Rio de Janeiro. Guanabara Editora.1987.

FREIRE, Paulo. Pedagogia da autonomia; saberes necessários á prática educativa. São Paulo: Paz e Terra. 1996.

GIROUX, Henry in :IMBERNÓN, F. (Org.) A educação no século XXI: os desafios do futuro imediato. Porto Alegre: ArtMed, 2000. 